\title{
Proteomic analysis of a non-virulent mutant of the phytopathogenic bacterium Erwinia chrysanthemi deficient in osmoregulated periplasmic glucans: change in protein expression is not restricted to the envelope, but affects general metabolism
}

Correspondence Jean-Marie Lacroix jean-marie.lacroix@univ-lille1.fr

Received 21 July 2006

Revised 23 October 2006

Accepted 2 November 2006

\section{Franck Bouchart,† Aurélie Delangle,† Jérôme Lemoine, Jean-Pierre Bohin and Jean-Marie Lacroix}

Unité de Glycobiologie Structurale et Fonctionnelle, UMR USTL-CNRS 8576 IFR 118, Université des Sciences et Technologies de Lille, 59655 Villeneuve d'Ascq Cedex, France

\begin{abstract}
Osmoregulated periplasmic glucans (OPGs) are general constituents of the envelope of Gram-negative bacteria. They are required for full virulence of bacterial phytopathogens such as Pseudomonas syringae, Xanthomonas campestris and Erwinia chrysanthemi. E. chrysanthemi is a pectinolytic $\gamma$-proteobacterium that causes soft rot disease on a wide range of plant species. In addition to the loss of virulence, opg mutants exhibit a pleiotropic phenotype that affects motility, bile-salt resistance, exoenzyme secretion, exopolysaccharide synthesis and membrane lipid composition. This is believed to be the first proteomic analysis of an OPG-defective mutant of $E$. chrysanthemi and it revealed that, in addition to the effects described, catabolic enzyme synthesis was enhanced and there was a greater abundance of some proteins catalysing the folding and degradation of proteins needed for various stress responses. Thus, in the opg mutant strain, loss of virulence was the result of a combination of envelope structure changes and cellular metabolism modifications.
\end{abstract}

\section{INTRODUCTION}

Osmoregulated periplasmic glucans (OPGs) are general periplasmic constituents of the envelope of many Gramnegative bacteria. Their common features are that (i) glucose is the sole constitutive sugar, and (ii) their abundance in the periplasm increases as the osmolarity of the medium decreases (Bohin \& Lacroix, 2006). OPG synthesis mutants of phytopathogenic bacteria fail to incite disease in their plant hosts (Bohin \& Lacroix, 2006). Mutants of Pseudomonas syringae pv. syringae devoid of OPGs show a reduced virulence on the common bean and its plant host, and fail to elicit a hypersensitive response on tobacco, a non-host plant (Bohin \& Lacroix, 2006; Loubens et al., 1993). Xanthomonas campestris pv. vesicatoria deficient in OPG biosynthesis shows an attenuated virulence in tomato (Minsavage et al., 2004). Erwinia chrysanthemi opg mutants are completely non-virulent when inoculated into potato tubers or chicory leaves (Page et al., 2001). In E. chrysanthemi, synthesis of the glucose backbone of OPGs is catalysed by both of the products of the $o p g G H$ operon: OpgG and OpgH catalyse

†These authors contributed equally to this work.

Abbreviations: OPG, osmoregulated periplasmic glucans; TCA, tricarboxylic acid. the synthesis of linear glucans containing $5-13$ glucose units joined by $\beta(1 \rightarrow 2)$ linkages and branched by $\beta(1 \rightarrow 6)$ linkages (Cogez et al., 2001). Mutations in opgG or opgH completely abolish OPG synthesis (Page et al., 2001).

E. chrysanthemi causes soft rot disease in a wide range of plant species, including crops of economic importance, such as vegetables and ornamentals. The virulence of $E$. chrysanthemi is strongly associated with the synthesis and secretion of exoenzymes, particularly pectinases and, to a lesser extent, cellulases and proteases. Pectinases and cellulases are secreted through a type II secretory apparatus known as Out, while proteases are secreted by a type I secretory system. Action of these enzymes causes maceration of the plant tissues, leads to the extension of the disease throughout the plant and provides bacteria with carbon sources (Hugouvieux-Cotte-Pattat et al., 1996). In addition to the non-virulent phenotype, opgG or opgH mutants exhibit a pleiotropic phenotype: colonies are mucoid (exopolysaccharide overproduction), and motility, bilesalt resistance and secretion of exoenzymes are reduced (Page et al., 2001). The $\mathrm{Opg}^{-}$phenotypes observed may be explained by a modification in envelope composition. One could hypothesize that the absence of virulence for opgG mutants is a consequence of the reduction of the secretion 
of exoenzymes. An outC mutant, defective in the Out type II secretory system, is more severely affected in pectinase secretion than an opgG mutant. When inoculated into potato tubers or chicory leaves, the virulence of the outC mutant is severely reduced, but not abolished. Coinoculation experiments with a mix of a mutant strain and the wild-type strain were performed in potato tubers. outC mutant cells grew normally in the mix, while no growth was observed for the opgG mutant cells contained in the mix. Thus, loss of virulence of opgG mutants does not result simply from a deficiency in exoenzyme secretion (Page et al., 2001). In addition, some of the OPGs are released into the medium by wild-type cells, indicating that OPGs play a role only within the periplasmic space of E. chrysanthemi (Cogez et al., 2001). It has often been reported that lack of an envelope component affects the surface properties of bacteria, and thus the interaction of bacteria with their environment.

In this paper, a comparative analysis of the soluble proteome of wild-type cells and opgG mutant cells of E. chrysanthemi was performed. Synthesis of several proteins governing essential cellular processes, such as protein folding and degradation, and carbohydrate catabolism, was increased. This suggests that the non-virulent phenotype of the opgG mutant is a complex phenomenon that includes, but is not restricted to, changes in the surface properties of the envelope.

\section{METHODS}

Bacterial strains and media. Wild-type E. chrysanthemi (EC3937) and its opgG::uidA-Kan (NFB3500) (Page et al., 2001) derivative strain, were grown at $30^{\circ} \mathrm{C}$, with vigorous shaking, in Luria-Bertani broth (LB) medium that contained $10 \mathrm{~g}$ bactotryptone $1^{-1}$ and $5 \mathrm{~g}$ yeast extract $1^{-1}$ (Difco), but did not contain $\mathrm{NaCl}$ (low-osmolarity medium, 90 mosmol $1^{-1}$ ).

Extraction of proteins. Bacteria were grown to mid-exponential phase, harvested by centrifugation and washed with $0.1 \mathrm{M}$ phosphate buffer, $\mathrm{pH} 6.6$, containing $20 \mathrm{mM} \mathrm{MgSO}_{4}$ and a protease inhibitor cocktail (Complete; Roche). The cell pellets were resuspended in the same buffer. Cells were disrupted by passing through a precooled French pressure cell at $1.4 \times 10^{7} \mathrm{~Pa}$. The lysates were centrifuged at $16000 \mathrm{~g}$ at $4{ }^{\circ} \mathrm{C}$ for $30 \mathrm{~min}$ to separate supernatants and pellets. The supernatants were treated by a mix of DNase I $\left(10 \mu \mathrm{g} \mathrm{ml}^{-1}\right)$ and RNase $\mathrm{A}\left(10 \mu \mathrm{g} \mathrm{ml}^{-1}\right)$ at $4{ }^{\circ} \mathrm{C}$ for $30 \mathrm{~min}$ and then centrifuged at $45000 \mathrm{~g}$ at $4^{\circ} \mathrm{C}$ for $30 \mathrm{~min}$. Four volumes of acetone were added to the supernatants and they were incubated at $-20^{\circ} \mathrm{C}$ for $1 \mathrm{~h}$ before centrifugation at $13000 \mathrm{~g}$ for $15 \mathrm{~min}$. The pellets were washed with $75 \%$ ethanol, dried and resuspended in solubilization buffer [7 M urea, $2 \mathrm{M}$ thiourea, $4 \%$ (w/v) CHAPS (Sigma-Aldrich), $65 \mathrm{mM}$ DTT (Proteomic Solutions), $0.25 \mathrm{mM}$ Triton X-100 and a protease inhibitor cocktail]. Protein concentration was determined by the Bradford test using BSA (Protein assay standard II; Bio-Rad) as a standard (Bradford, 1976). Total protein concentration was determined according to Stickland (1951).

Electrophoresis of proteins. IEF was performed using $18 \mathrm{~cm}$ IPG strips (Immobiline DryStrip; GE Healthcare), with a linear gradient of $\mathrm{pH}$ ranging from 3 to 10 . Protein solutions $(600 \mu \mathrm{g}$ in $200 \mu \mathrm{l}$ of solubilization buffer) were mixed with $200 \mu$ l rehydration buffer [8 M urea, $2 \mathrm{M}$ thiourea, 2\% (w/v) CHAPS, $100 \mathrm{mM}$ DTT, $2 \%$ (v/v) ampholytes (pH 3-10; Proteomic Solutions) and $0.001 \%$ bromophenol blue]. After $16 \mathrm{~h}$ rehydration, IEF was performed using a pHaser isoelectric focusing system (Proteomic Solutions) at $20^{\circ} \mathrm{C}$ for 100000 Volt hours ( $\mathrm{V} \mathrm{h}$ ), from 0 to $5000 \mathrm{~V}$ over $24 \mathrm{~h}$. Before the second dimension, strips were immersed for $20 \mathrm{~min}$ in equilibration buffer [6 M urea, $30 \%(\mathrm{v} / \mathrm{v})$ glycerol, $2 \%(\mathrm{w} / \mathrm{v})$ SDS, $0.375 \mathrm{M}$ Tris/HCl ( $\mathrm{pH} 8.8)$ and $2 \%$ DTT]. SDS-PAGE was carried out on a $12 \% \mathrm{w} / \mathrm{v}$ polyacrylamide resolving gel (Duracryl $30 \%$; Proteomic
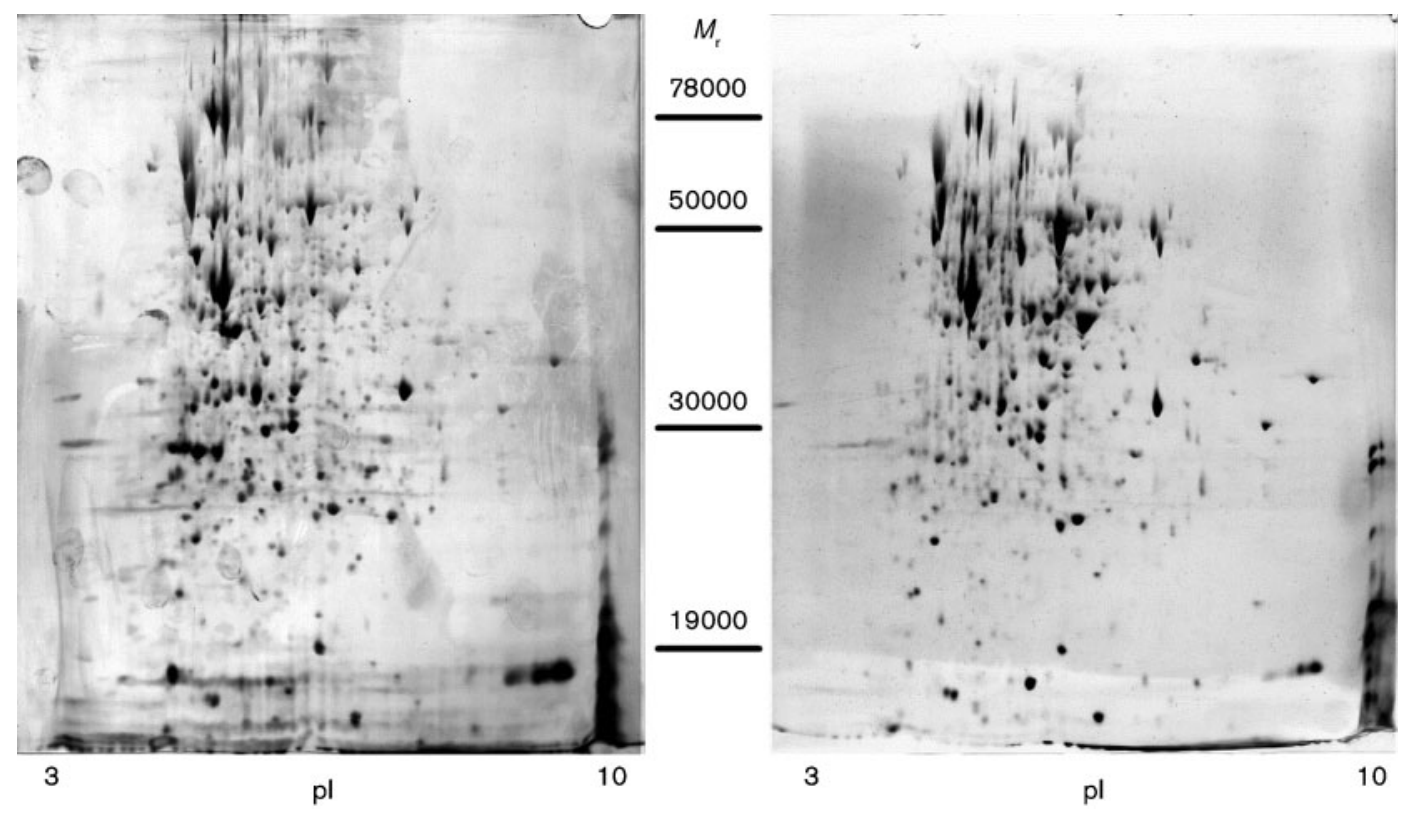

Fig. 1. Silver-stained 2D gels of the soluble proteome from exponential-phase bacteria grown in LB medium without $\mathrm{NaCl}$. Left, E. chrysanthemi EC3937; right, the opgG-derivative strain NFB3500. 
Solutions) in running buffer (25 mM Tris, $192 \mathrm{mM}$ glycine, $0.1 \%$ SDS, $\mathrm{pH}$ 8.3). Proteins were visualized by staining gels with silver nitrate solution, according to Rabilloud (1999).

Analysis of 2D electrophoresis gels. Image analysis of 2D electrophoresis gels was performed using the Melanie Image Master 2D Platinum 5 software (GE Healthcare) and three gels from each condition. The proteome profile of wild-type E. chrysanthemi EC3937 was used as a reference pattern for spot analysis and all spot files were matched to the reference pattern. The intensity of each spot was normalized by total spot intensity.

Protein identification by MALDI-TOF MS. Spots were excised from gel and washed three times with $50 \mu \mathrm{l} 25 \mathrm{mM}$ ammonium bicarbonate and once with $50 \%$ acetonitrile in $25 \mathrm{mM}$ ammonium bicarbonate. The supernatants were discarded and the gel pieces were dried. The proteins were digested in-gel with $20 \mathrm{ng}$ porcine trypsin $\mu \mathrm{l}^{-1}$ (Promega) in $25 \mathrm{mM}$ ammonium bicarbonate. The digestion was performed overnight at $37^{\circ} \mathrm{C}$. The resulting peptides were extracted from the gel by $1 \%$ formic acid and then by $50 \%$ acetonitrile in $1 \%$ formic acid. Supernatants from both the mutant and the wild-type were pooled and peptides were dried and resuspended in $0.5 \%$ formic acid. A $0.5 \mu \mathrm{l}$ volume of the peptide solution was directly mixed with $1 \mu \mathrm{l}$ 2,5-dihydroxybenzoic acid matrix $\left[10 \mathrm{mg} \mathrm{ml}^{-1}\right.$ in methanol/water $\left.(7: 3, \mathrm{v} / \mathrm{v})\right]$ on the stainless steel target and allowed to crystallize in a gentle stream of air. Peptide mass fingerprint spectra were manually acquired on a MALDI-TOF MS instrument (DE STR Pro; Applied Biosystems). An in-house MASCOT (Matrix Sciences; http://www.matrixscience. $\mathrm{com} /$ ) search engine was used for protein identification against the E. chrysanthemi database (http://asap.ahabs.wisc.edu/asap/ASAP1.htm).

\section{RESULTS AND DISCUSSION}

\section{Growth of the E. chrysanthemi opgG mutant}

Bacterial cells were grown in $\mathrm{LB}$ medium without $\mathrm{NaCl}$, and growth was found to be similar for wild-type cells (EC3937) and opgG mutant cells (NFB3500). Total protein concentration was measured using a $50 \mathrm{ml}$ culture sample taken at mid-exponential phase $\left(\mathrm{OD}_{620} 0.4\right)$, and only a slight difference, if any, was observed between the two strains: 0.12

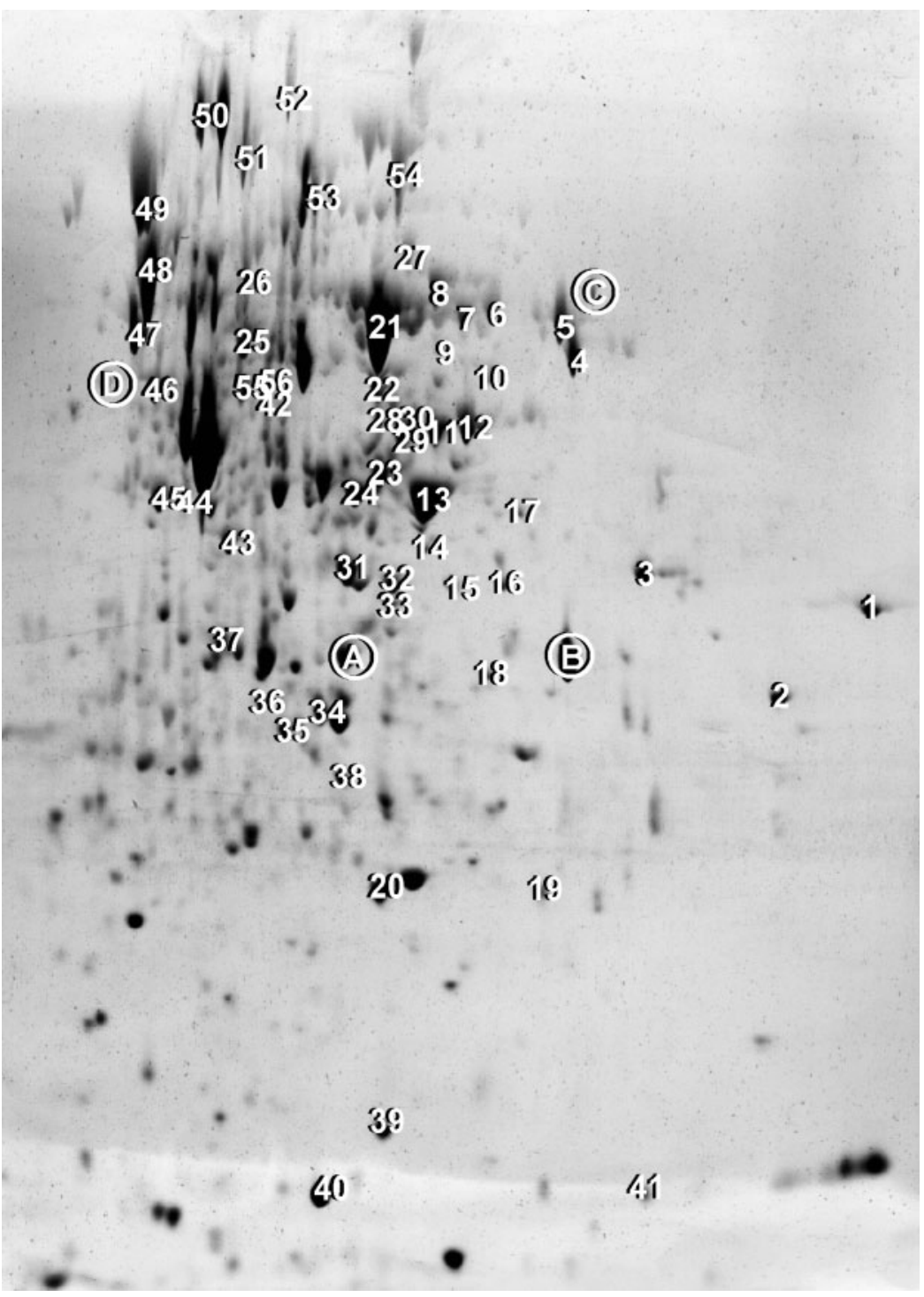

Fig. 2. Enlargement of the silver-stained 2D gel of the soluble proteome of the E. chrysanthemi opgG-derivative NFB3500. The numbers indicate spots that were identified. Spots A, B, C and D are landmarks for Melanie Image Master 2D Platinum 5 software calibration. 


\begin{tabular}{|c|c|c|c|c|c|c|c|c|c|c|}
\hline $\begin{array}{l}\text { Spot no.* and } \\
\text { function }\end{array}$ & $\begin{array}{c}\text { Accession } \\
\text { no. } \dagger\end{array}$ & pI & $\begin{array}{c}\text { Mass } \\
(\mathbf{k D a}) \dagger\end{array}$ & Gene $\dagger$ & Location & Ratio $\ddagger$ & Putative function $\dagger$ & Coverage & Score $\$$ & $\begin{array}{l}\text { No. of peptides } \\
\text { matched }\end{array}$ \\
\hline \multicolumn{11}{|c|}{ Polysaccharide synthesis } \\
\hline 25 & 15220 & 5.4 & 51.2 & $\operatorname{cps} G$ & Cytoplasm & 2.3 & Phosphomannomutase & 22 & 67 & 10 \\
\hline 18 & 15224 & 6.2 & 35 & $f_{c l}$ & Cytoplasm & 1.6 & GDP-L-fucose synthetase & 27 & 52 & 7 \\
\hline 33 & 20562 & 5.9 & 36.9 & gale & Cytoplasm & 2.8 & UDP-glucose 4-epimerase & 25 & 68 & 7 \\
\hline 32 & 19489 & 5.8 & 32.3 & galF & Cytoplasm & 3 & Glucose-1-phosphate uridylyltransferase & 39 & 89 & 10 \\
\hline 37 & 20647 & 5.2 & 33.4 & galU & Cytoplasm & 8.3 & UTP-glucose-1-phosphate uridylyltransferase & 30 & 56 & 8 \\
\hline 24 & 20463 & 5.7 & 39.8 & $r f f G$ & Cytoplasm & 5.1 & dTDP-glucose 4,6-dehydratase & 31 & 86 & 9 \\
\hline $23 / 28$ & 19487 & 5.8 & 43.4 & ugd & Cytoplasm & 5 & UDP-glucose dehydrogenase & $21 / 54$ & $65 / 282$ & $6 / 22$ \\
\hline \multicolumn{11}{|l|}{ Regulation } \\
\hline 51 & 16313 & 5.2 & 67.5 & bipA & Cytoplasm & 1.5 & Ribosome-binding GTPase & 29 & 77 & 16 \\
\hline \multicolumn{11}{|l|}{ Detoxification } \\
\hline 20 & 17551 & 5.8 & 22.4 & No name & Cytoplasm & 1.9 & Alkyl hydroperoxide reductase & 32 & 63 & 7 \\
\hline \multicolumn{11}{|c|}{ Amino acid metabolism } \\
\hline 11 & 18183 & 6.1 & 45.3 & glyA & Cytoplasm & 4.5 & Serine hydroxymethyl transferase & 29 & 66 & 14 \\
\hline \multicolumn{11}{|c|}{ Lipid metabolism } \\
\hline 4 & 17046 & 6.7 & 49.3 & $\operatorname{accC}$ & Cytoplasm & 2.2 & Biotin carboxylase & 27 & 51 & 14 \\
\hline 39 & 19707 & 5.9 & 19.1 & $f a b A$ & Cytoplasm & 0.58 & $\beta$-Hydroxydecanoyl thioester dehydratase & 27 & 69 & 5 \\
\hline 35 & 19259 & 5.4 & 28.2 & fabI & Cytoplasm & 0.47 & Enoyl-ACP reductase & 27 & 85 & 7 \\
\hline \multicolumn{11}{|c|}{ Nucleotide metabolism } \\
\hline 22 & 15203 & 5.8 & 47.3 & purA & Cytoplasm & 4.4 & Adenylosuccinate synthase & 18 & 75 & 11 \\
\hline 30 & 17763 & 5.9 & 51.5 & purB & Cytoplasm & 8.3 & Adenylosuccinate lyase & 38 & 173 & 19 \\
\hline \multicolumn{11}{|c|}{ Carbohydrate metabolism } \\
\hline 52 & 19243 & 5.5 & 99.2 & aceE & Cytoplasm & 1.1 & Subunit of pyruvate dehydrogenase & 26 & 124 & 20 \\
\hline 31 & 15181 & 5.6 & 39.1 & $f b a A$ & Cytoplasm & 4.7 & Fructose-bisphosphate aldolase class II & 20 & 50 & 7 \\
\hline 13 & 18196 & 6.6 & 44.4 & $\operatorname{gan} A$ & Periplasm & 4.4 & Endogalactanase & 34 & 95 & 15 \\
\hline 5 & 15062 & 6.5 & 56.7 & $g l p D$ & Cytoplasm & 5 & Glycerol-3-phosphate dehydrogenase & 38 & 174 & 25 \\
\hline 21 & 20398 & 5.8 & 56 & $g l p K$ & Cytoplasm & 3.3 & Glycerol kinase & 29 & 223 & 17 \\
\hline 14 & 15029 & 6.1 & 40.8 & $g l p Q$ & Cytoplasm & 2.8 & Glycerophosphoryl diester phosphodiesterase & 50 & 96 & 18 \\
\hline 12 & 16958 & 6.2 & 48.1 & gltA & Cytoplasm & 2.6 & Citrate synthase & 18 & 67 & 9 \\
\hline 55 & 46981 & 5.3 & 51.5 & gnd & Cytoplasm & 1.9 & 6-Phosphogluconate dehydrogenase & 23 & 55 & 10 \\
\hline 38 & 20551 & 5.7 & 28.6 & $g p m A$ & Cytoplasm & 2.9 & Phosphoglyceromutase 1 & 22 & 53 & 6 \\
\hline 27 & 17827 & 5.9 & 61.2 & $p g i$ & Cytoplasm & 5.6 & Phosphoglucose isomerase & 30 & 61 & 13 \\
\hline 50 & 19893 & 5.1 & 87.2 & ppsA & Cytoplasm & 0.59 & Phosphoenolpyruvate synthase & 22 & 86 & 15 \\
\hline 53 & 16955 & 5.7 & 64.5 & $s d h A$ & Cytoplasm & 3.9 & Succinate dehydrogenase & 26 & 114 & 17 \\
\hline 26 & 20198 & 5.3 & 62.9 & $s f c A$ & Cytoplasm & 0.42 & Malate dehydrogenase (gluconeogenesis) & 26 & 101 & 13 \\
\hline 54 & 15185 & 5.9 & 71.9 & $t k t A$ & Cytoplasm & 4.2 & Transketolase 1 isoenzyme & 21 & 107 & 14 \\
\hline 43 & 20276 & 5.3 & 40 & yiaY & Cytoplasm & 0.3 & Alcohol dehydrogenase & 54 & 66 & 19 \\
\hline
\end{tabular}


Table 1. cont

\begin{tabular}{|c|c|c|c|c|c|c|c|c|c|c|}
\hline $\begin{array}{l}\text { Spot no.* and } \\
\text { function }\end{array}$ & $\begin{array}{c}\text { Accession } \\
\text { no. } \dagger\end{array}$ & pI & $\begin{array}{l}\text { Mass } \\
(\mathbf{k D a}) \dagger\end{array}$ & Gene $\dagger$ & Location & Ratio $\ddagger$ & Putative function $\dagger$ & Coverage & Score $\$$ & $\begin{array}{c}\text { No. of peptides } \\
\text { matched }\end{array}$ \\
\hline \multicolumn{11}{|c|}{ Protein folding and degradation } \\
\hline 42 & 19559 & 5.4 & 46.7 & $\operatorname{clp} X$ & Cytoplasm & 3 & Subunit of ClpXP protease & 32 & 116 & 12 \\
\hline 10 & 15693 & 7.7 & 47.9 & $\operatorname{deg} Q$ & Periplasm & 2.7 & Serine endoprotease & 34 & 181 & 15 \\
\hline $36 / 56$ & 15461 & 6.1 & 29.9 & $f k p A$ & Periplasm & ॥ & FKPB chaperone & $37 / 39$ & $67 / 93$ & $12 / 13$ \\
\hline 48 & 18669 & 4.9 & 57.5 & groL & Cytoplasm & 1.2 & GroEL subunit of GroES/GroEL chaperone & 57 & 118 & 40 \\
\hline 40 & 18667 & 5.7 & 10.5 & gros & Cytoplasm & 2.7 & GroES subunit of GroES/GroEL chaperone & 55 & 71 & 5 \\
\hline 6 & 16590 & 6.4 & 54.8 & рерА & Cytoplasm & 4.9 & Aminopeptidase & 17 & 55 & 9 \\
\hline 29 & 20133 & 5.9 & 46.9 & рерв $B$ & Cytoplasm & 8.4 & Aminopeptidase & 37 & 154 & 18 \\
\hline 9 & 17747 & 6.1 & 50.4 & pepQ & Cytoplasm & 0.77 & Proline dipeptidase & 18 & 53 & 7 \\
\hline 47 & 20523 & 4.9 & 48.2 & tig & Cytoplasm & 3.4 & Trigger factor & 62 & 74 & 34 \\
\hline \multicolumn{11}{|l|}{ Transport } \\
\hline 46 & 14785 & 5 & 50.3 & $\operatorname{atpD}$ & Cytoplasm & 0.7 & ATP synthase $\beta$ subunit & 37 & 76 & 11 \\
\hline 2 & 18320 & 8.6 & 34.1 & gltI & Periplasm & 1.8 & Glutamate-binding protein & 61 & 149 & 21 \\
\hline 34 & 18377 & 6.5 & 35.8 & $m g l B$ & Periplasm & 2.4 & Galactose-binding protein & 56 & 134 & 16 \\
\hline 8 & 20639 & 6.4 & 61.3 & $o p p A$ & Periplasm & 3 & Oligopeptide-binding protein & 38 & 105 & 22 \\
\hline 16 & 19819 & 7.6 & 41 & potF & Periplasm & 1.5 & Putrescine-binding protein & 22 & 59 & 8 \\
\hline 3 & 20233 & 8.8 & 36.8 & Unknown & Periplasm & 2.9 & Iron-binding protein & 30 & 61 & 11 \\
\hline \multicolumn{11}{|l|}{ Transcription } \\
\hline $44 / 45$ & 16922 & 5 & 36.6 & rpoA & Cytoplasm & 2 & RNA polymerase $\alpha$ subunit & $38 / 40$ & $75 / 59$ & $11 / 17$ \\
\hline \multicolumn{11}{|l|}{ Translation } \\
\hline 49 & 46566 & 4.9 & 61.3 & rpsA & Cytoplasm & 1.6 & S1 protein of 30 S ribosomal subunit & 55 & 210 & 29 \\
\hline 15 & 20829 & 6.1 & 37.7 & $\operatorname{trpS}$ & Cytoplasm & 2.5 & Tryptophanyl-tRNA synthetase & 21 & 102 & 10 \\
\hline \multicolumn{11}{|c|}{ Unknown function } \\
\hline 17 & 15570 & 7.8 & 45.5 & $y d g J$ & Unknown & 3.5 & Unknown & 25 & 108 & 10 \\
\hline 41 & 15573 & 8.5 & 17.1 & Unknown & Unknown & 9.1 & Unknown & 48 & 103 & 8 \\
\hline 7 & 47171 & 6.3 & 50.7 & Unknown & Unknown & 2.9 & Unknown & 18 & 65 & 10 \\
\hline 19 & 47181 & 6.6 & 25.6 & Unknown & Unknown & 0.42 & Unknown & 42 & 69 & 9 \\
\hline
\end{tabular}

${ }^{\star}$ Spot numbers refer to the proteins labelled in Fig. 2.

$\dagger$ As given in the E. chrysanthemi database (http://asap.ahabs.wisc.edu/asap/ASAP1.htm).

$\ddagger$ ppot intensity for each protein derived from the $\operatorname{pg} g$ mutant cells with respect to the protein derived from the wild-type cells.

$\$ S$ core is $(-10) \log P ; P$ is the probability that the observed match is a random event.

IIFkpA was detected in the opgG mutant strain NFB3500 only. 
and $0.11 \mathrm{mg} \mathrm{ml}^{-1}$ for the wild-type and the mutant, respectively.

\section{Identification of proteins with an altered pattern of synthesis}

The properties of several $\mathrm{Opg}^{-}$phenotypes suggested that envelope perturbation had occurred. To quantify the amount of envelope perturbation, 1D SDS-PAGE of membrane proteins was performed. No significant difference was observed between the protein patterns for the opgG mutant and the wild-type, indicating that the synthesis of major membrane proteins was only slightly affected in the opgG mutant strain (data not shown). Thus, to get better insight into the $\mathrm{Opg}^{-}$phenotype, a 2D comparative analysis of the soluble proteome of the two strains was performed.

The soluble proteins of E. chrysanthemi extracted from the wild-type strain EC3937, and from the opgG strain NFB3500, were separated on high-resolution 2D electrophoresis gels ( $\mathrm{pH} \mathrm{3-10)}$ (Figs 1 and 2). Most of the spots observed were located in a pI range of 4.6-6.6. Three analytical gels for each condition were analysed and compared by the Melanie 5 software, which generates standardized synthetic images. The two resulting synthetic gels allowed detection of 275 and 218 spots for the wild-type and the opgG mutant, respectively. Spots of 55 polypeptides, showing differences in intensity between the wild-type and the mutant, were excised from the gels, submitted to trypsin digestion and analysed by MALDI-TOF MS. The experimental mass fingerprint was compared with the genomic database of E. chrysanthemi using Mascot software. For each polypeptide, the mass and $\mathrm{pI}$ obtained from the $2 \mathrm{D}$ analytical gels were in agreement with the theoretical mass and $\mathrm{pI}$ of the deduced protein. Functions were assigned to 51 of the 55 spots (Table 1). As expected, most of the proteins (42) originated from the cytoplasm, while 9 originated from the periplasm. The proteins were assigned into 11 classes of cellular function, with almost half (25) being assigned to protein folding and degradation and carbohydrate metabolism. We focused on proteins showing a differential expression level of around 2 or more and, among these, only three were expressed to a lesser extent in the mutant strain NFB3500.

\section{Envelope composition is modified in opgG cells}

In E. chrysanthemi, as in other Gram-negative bacteria, one of the phenotypes encountered in opg mutants is overproduction of the exopolysaccharides known to protect cells from environmental injury (Bohin, 2000). We report here the overexpression of five genes needed for exopolysaccharide biosynthesis. cps $G$ encodes a phosphomannomutase (Stevenson et al., 1996). galE, galU and galF encode proteins that catalyse steps in LPS core biosynthesis. GalE is the UDP-glucose 4-epimerase, and GalU and GalF are the two subunits of the UTP-glucose-1-phosphate uridylyltransferase catalysing the reversible reaction of UTP and glucose 1-phosphate into UDP-glucose. Finally, ugd encodes
UDP-glucose dehydratase and, in addition, it participates in a modification of the core of LPS, which confers resistance toward antimicrobial peptides in Salmonella enterica and Yersinia pestis (Mouslim \& Groisman, 2003; Winfield et al., 2005). Furthermore, RffG production was increased; this protein is a dTDP-glucose 4,6-dehydratase needed for the synthesis of both $\mathrm{O}$ antigen and enterobacterial common antigen (Keseler et al., 2005). An increase in LPS biosynthesis has already been shown in a comparative quantification of monosaccharide production between the $\operatorname{opg} G$ and wildtype E. chrysanthemi strains. The analysis revealed a 1.5 -fold increase in the level of Kdo, which is the specific monosaccharide of the core of the LPS, and in the level of $\mathrm{N}$-acetylglucosamine, which is part of the lipid A moiety of LPS, in the opgG mutant strain, while the peptidoglycan level remained stable (Bohin et al., 2005).

Lipid metabolism was enhanced and fatty acid saturation was decreased in $\operatorname{opg} G$ cells. Synthesis of a subunit of the acetyl CoA carboxylase (AccC protein), which participates in the first step of fatty acid synthesis, was increased, while synthesis of the enoyl-ACP reductase (FabI protein), which is implicated in the biosynthesis of unsaturated fatty acids, was reduced. Biochemical identification and quantification of the fatty acid composition of the wild-type and the $o p g G$ mutant of E. chrysanthemi EC3937 revealed a 20-30\% reduction in the amount of $\mathrm{C}_{16: 1}$ and $\mathrm{C}_{18: 1}$ unsaturated fatty acids in the membrane phospholipids of the opgG mutant cells (Bohin et al., 2005). Furthermore, expression of enzymes controlling glycerol catabolism (GlpD, GlpQ and $\mathrm{GlpK}$ ) was increased. These findings suggest a rearrangement of the envelope structure in the opgG mutant cells.

\section{Catabolic enzyme synthesis is enhanced in opgG cells}

In this work, transport systems were detected by their soluble periplasmic-binding-protein component (Table 1), since all of these components belong to the $\mathrm{ABC}$ transporter family of proteins. Increased synthesis of two proteins, which are components of the nutrient uptake system, was detected: MglB, a galactose-binding protein; and OppA, the oligopeptide-binding protein serving for nutrition by peptides and recycling of muropeptides (Monnet, 2003). In addition, synthesis of a periplasmic endogalactanase (GanA) was increased. The gene encoding endogalactanase belongs to an operon controlling galactan uptake (A. Delangle, A.-F. Prouvost, V. Cogez, J.-P. Bohin, J.-M. Lacroix \& N. Hugouvieux-Cotte-Pattat, unpublished results). Nutrient uptake appeared to be stimulated in the opg $G$ mutant.

Enzymes related to carbohydrate metabolism were detected. All of the metabolic pathways discussed are according to Keseler et al. (2005). A gene from one of the pathways, $s f c A$, encoding the malic enzyme, was expressed to a lesser extent in the mutant. This enzyme catalyses the transformation of malate to pyruvate in one of the two possible gluconeogenesis pathways. Three overexpressed 
genes encoded enzymes that are part of the glycolytic pathway. Phosphoglucose isomerase (Pgi) catalyses the first step of glucose degradation. The major fructose-bisphosphate aldolase (FbaA) displays $95 \%$ of its activity in glycolysis and is not required for gluconeogenesis in Escherichia coli. Synthesis of the phosphoglycerate mutase (encoded by $\mathrm{g} p m A$ ) is increased in other bacterial species under various environmental stress conditions (Sanchez et al., 2005). In addition, synthesis of the three enzymes of glycerol catabolism (GlpD, GlpQ and GlpK), which catalyse conversion of glycerol into dihydroxyacetone phosphate, was increased. The galE, galU and galF genes, whose products are needed for polysaccharide synthesis and also for galactose degradation, were overexpressed. Furthermore, increased levels of two proteins catalysing steps in the pentose phosphate pathway were observed: 6-phosphogluconate dehydrogenase (encoded by gnd) and the major transketolase (encoded by $t k t A$ ). In E. coli, transketolase is the key enzyme regulating the flux between the pentose phosphate pathway and glycolysis. Transketolase is essential for pentose catabolism (Romeo \& Snoep, 2005); increased synthesis leads to an increase in glyceraldehyde 3-phosphate and fructose 6-phosphate, thus supplying glycolysis with intermediates at two different levels. In addition, transketolase plays a protective role during oxidative stress in Saccharomyces cerevisiae (Slekar et al., 1996) and its synthesis is increased in conditions of bile-salt stress in Bifidobacterium longum (Sanchez et al., 2005). Two genes encoding enzymes of the tricarboxylic acid (TCA) cycle were overexpressed: gltA and $s d h A$, encoding citrate synthase and succinate dehydrogenase respectively. Increased synthesis of the latter enzyme suggested that the TCA cycle was closed, and functioned for both precursor and energy synthesis. In E. coli under aerobic conditions, the TCA cycle was not closed, stop before succinate, and was almost exclusively dedicated to precursor synthesis (Romeo \& Snoep, 2005). Data indicate that in E. coli, an increase in energy requirement due to temperature-induced production of recombinant proteins is associated with succinate dehydrogenase overexpression and an increase in respiration (Hoffmann et al., 2002). This suggests that energy metabolism is stimulated in response to OPG deficiency.

\section{Protein folding and degradation are stimulated in opgG cells}

It is well documented that the stress response includes increased synthesis of three classes of proteins: chaperones, proteases and peptidases. Synthesis of seven proteins governing protein folding or degradation was increased in the opgG mutant (Table 1). FkpA, a periplasmic chaperone with a cis-trans prolyl isomerase activity (Justice et al., 2005), was detected in the proteome of the opgG mutant strain only. In E. coli, the $f k p A$ gene is activated by an increase in unfolded envelope proteins caused by stress conditions affecting envelope integrity (Dartigalongue et al., 2001). FkpA has been implicated in the heat-shock response and intracellular survival of S. enterica sv. Typhimurium (Horne et al., 1997).
Intracellular survival depends on the Mip protein, which is an FkpA-like protein in Legionella pneumophila (Cianciotto et al., 1990). Five other proteins were located in the cytoplasm. Tig is a chaperone with cis-trans prolyl isomerase activity that is bound to the ribosome and cooperates with the DnaK chaperone to promote folding of newly synthesized proteins (Deuerling et al., 1999). For GroEL/GroES, another chaperone, synthesis of the regulatory component GroES was found to be significantly increased (Table 1). DegQ is a periplasmic serine endoprotease that degrades denatured or unfolded proteins that are produced in normal growth conditions, or are accumulated after various stress conditions (Yohannes et al., 2004; Kolmar et al., 1996). ClpX, the ATPase subunit of the ClpXP protease, was overexpressed, while ClpP, the catalytic subunit of this protease, was not detected. It is possible that we were not able to detect ClpP, or, alternatively, that only the clpX gene was overexpressed. The $p e p A$ and $p e p B$ genes, encoding two cytoplasmic peptidases, were overexpressed. In addition to its peptidase activity, PepA is involved in the regulation of virulence factors in Vibrio cholerae (Behari et al., 2001). Furthermore, it has been reported that OppA and MglB, in addition to their role in substrate uptake, could play a role in protein folding. These chaperone-like proteins may participate in protection from stress in the periplasm (Richarme \& Caldas, 1997). The results presented here suggest that $E$. chrysanthemi opgG strain responds to OPG deficiency by increasing the expression of several stress-response proteins.

\section{Concluding remarks}

The present work constitutes what we believe to be the first proteomic analysis of the production of soluble proteins in an opg mutant. Despite the global and non-exhaustive character of this analysis, it confirms the phenotypes previously described, and reveals several new phenotypes. E. chrysanthemi responds to OPG deficiency by activating cellular processes known to protect the cell against many environmental stresses, suggesting that the opgG strain is impaired in the perception of its environment. Our data demonstrate that the non-virulent character of opgG mutants does not result simply from modification in envelope composition leading to an impaired interaction between the surfaces of the bacteria and its host cell. Lack of infectivity is also a result of alterations in metabolism and fitness of opgG cells.

\section{ACKNOWLEDGEMENTS}

We thank Anne-Sophie Vercoutter-Edouart for helpful discussion and expert technical advice. We thank Jean-Claude Michalski for critical reading of the manuscript.

\section{REFERENCES}

Behari, J., Stagon, L. \& Calderwood, S. B. (2001). pepA, a gene mediating $\mathrm{pH}$ regulation of virulence genes in Vibrio cholerae. J Bacteriol 183, 178-188. 
Bohin, J.-P. (2000). Osmoregulated periplasmic glucans in Proteobacteria - a minireview. FEMS Microbiol Lett 186, 11-19.

Bohin, A., Bouchart, F., Richet, C., Kol, O., Leroy, Y., Timmerman, P., Huet, G., Bohin, J.-P. \& Zanetta, J.-P. (2005). GC/MS identification and quantification of constituents of bacterial lipids and glycoconjugates obtained after methanolysis as heptafluorobutyrate derivatives. Anal Biochem 340, 231-244.

Bohin, J.-P. \& Lacroix, J.-M. (2006). Osmoregulation in the periplasm. In The Periplasm, pp. 325-341. Edited by M. Ehrmann. Washington, DC: American Society for Microbiology.

Bradford, M. M. (1976). A rapid and sensitive method for the quantitation of microgram quantities of protein utilizing the principle of protein-dye binding. Anal Biochem 72, 248-254.

Cianciotto, N. P., Eisenstein, B. I., Mody, C. H. \& Engelberg, N. C. (1990). A mutation in the mip gene results in an attenuation of Legionella pneumophila virulence. J Infect Dis 162, 121-126.

Cogez, V., Talaga, P., Lemoine, J. \& Bohin, J.-P. (2001). Osmoregulated periplasmic glucans of Erwinia chrysanthemi. J Bacteriol 183, 3127-3133.

Dartigalongue, C., Missiakas, D. \& Raina, S. (2001). Characterization of the Escherichia coli sigma E regulon. J Biol Chem 276, 20866-20875.

Deuerling, E., Schulze-Specking, A., Tomoyasu, T., Mogk, A. \& Bukau, B. (1999). Trigger factor and DnaK cooperate in folding of newly synthesized proteins. Nature 400, 693-696.

Hoffmann, F., Weber, J. \& Rinas, U. (2002). Metabolic adaptation of Escherichia coli during temperature-induced recombinant protein production: 2. Redirection of metabolic fluxes. Biotechnol Bioeng 80, 313-319.

Horne, S. M., Kottom, T. J., Nolan, L. K. \& Young, K. D. (1997). Decreased intracellular survival of an $f k p A$ mutant of Salmonella typhimurium Copenhagen. Infect Immun 65, 806-810.

Hugouvieux-Cotte-Pattat, N., Condemine, G., Nasser, W. \& Reverchon, S. (1996). Regulation of pectinolysis in Erwinia chrysanthemi. Annu Rev Microbiol 50, 213-257.

Justice, S. S., Hunstad, D. A., Harper, J. R., Duguay, A. R., Pinkner, J. S., Bann, J., Frieden, C., Silhavy, T. J. \& Hultgren, S. J. (2005). Periplasmic peptidyl prolyl cis-trans isomerases are not essential for viability, but SurA is required for pilus biogenesis in Escherichia coli. J Bacteriol 187, 7680-7686.

Keseler, I. M., Collado-Vides, J., Gama-Castro, S., Ingraham, J., Paley, S., Paulsen, I. T., Peralta-Gil, M. \& Karp, P. D. (2005). EcoCyc: a comprehensive database resource for Escherichia coli. Nucleic Acids Res 33, 334-337.

Kolmar, H., Waller, P. R. \& Sauer, R. T. (1996). The DegP and DegQ periplasmic endoproteases of Escherichia coli: specificity for cleavage sites and substrate conformation. J Bacteriol 178, 5925-5929.

Loubens, I., Debarbieux, L., Bohin, A., Lacroix, J.-M. \& Bohin, J.-P. (1993). Homology between a genetic locus $(m d o A)$ involved in the osmoregulated biosynthesis of periplasmic glucans in Escherichia coli and a genetic locus ( $h r p M)$ controlling pathogenicity of Pseudomonas syringae. Mol Microbiol 10, 329-340.

Minsavage, G. V., Mudgett, M. B., Stall, R. E. \& Jones, J. B. (2004). Importance of opgHXcv of Xanthomonas campestris pv. vesicatoria in host-parasite interactions. Mol Plant Microbe Interact 17, 152-161.

Monnet, V. (2003). Bacterial oligopeptide-binding proteins. Cell Mol Life Sci 60, 2100-2114.

Mouslim, C. \& Groisman, E. A. (2003). Control of the Salmonella ugd gene by three two-component regulatory systems. Mol Microbiol 47, 335-344.

Page, F., Altabe, S., Hugouvieux-Cotte-Pattat, N., Lacroix, J.-M., Robert-Baudouy, J. \& Bohin, J.-P. (2001). Osmoregulated periplasmic glucan synthesis is required for Erwinia chrysanthemi pathogenicity. J Bacteriol 183, 3134-3141.

Rabilloud, T. (1999). Silver staining of 2-D electrophoresis gels. Methods Mol Biol 112, 297-305.

Richarme, G. \& Caldas, D. T. (1997). Chaperone properties of the bacterial periplasmic substrate-binding proteins. J Biol Chem 272, 15607-15612.

Romeo, T. \& Snoep, J. L. (2005). Glycolysis and flux control. In Escherichia coli and Salmonella: Cellular and Molecular Biology. Edited by F. C. Neidhardt, A. Bock, R. Curtiss, III, J. B. Kaper, T. Nyström, K. E. Rudd \& C. L. Squires; http://www.ecosal.org/ecosal/ index.jsp. Washington, DC: American Society for Microbiology.

Sanchez, B., Champomier-Vergès, M.-C., Anglade, P., Baraige, F., de los Reyes-Gavilan, C. G., Margolles, A. \& Zagorec, M. (2005). Proteomic analysis of global changes in protein expression during bile salt exposure of Bifidobacterium longum NCIMB 8809. J Bacteriol 187, 5799-5808.

Slekar, K. H., Kosman, D. J. \& Culotta, V. C. (1996). The yeast copper/zinc superoxide dismutase and the pentose phosphate pathway play overlapping roles in oxidative stress protection. $J$ Biol Chem 271, 28831-28836.

Stevenson, G., Adrianopoulos, K., Hobbs, M. \& Reeves, P. R. (1996). Organization of the Escherichia coli K-12 gene cluster responsible for production of the extracellular polysaccharide colanic acid. J Bacteriol 178, 4885-4893.

Stickland, L. H. (1951). The determination of small quantities of bacteria by means of the biuret reaction. J Gen Microbiol 5, 698-703.

Winfield, M. D., Latifi, T. \& Groisman, E. A. (2005). Transcriptional regulation of the 4-amino-4-deoxy-L-arabinose biosynthetic genes in Yersinia pestis. J Biol Chem 280, 14765-14772.

Yohannes, E., Barnhart, D. M. \& Slonczewski, J. L. (2004). $\mathrm{pH}$-dependent catabolic protein expression during anaerobic growth of Escherichia coli K12. J Bacteriol 186, 192-199.

Edited by: M. S. Ullrich 